RU Рациональные приемы запоминания иноязычной лексики в системе профильной подготовки студентов вуза: теоретический и практический аспекты

\author{
Кирюшина О. В.
}

\begin{abstract}
Аннотация. Цель исследования - выявить пути повышения качества усвоения иноязычной лексики студентами профиля подготовки «Иностранный язык». В статье рассматриваются особенности обучения лексическому аспекту иностранного языка, делается акцент, с одной стороны, на объективных трудностях изучения новых лексических единиц, с другой стороны, на важности формирования у студентов достаточного по объему активного словарного запаса. Отмечается факт плохого запоминания обучающимися новой иноязычной лексики, раскрываются некоторые причины данного явления с опорой на статистические данные проведенного исследования. Одной из главных причин является недостаточное использование в процессе обучения рациональных приемов обучения иноязычной лексике. Далее в статье анализируется ряд рациональных приемов запоминания иностранных слов, приводятся данные о степени использования студентами этих приемов, предлагаются методические рекомендации по улучшению качества усвоения иноязычной лексики. Научная новизна исследования заключается в попытке полного и всестороннего рассмотрения проблемы запоминания иноязычных лексических единиц в ракурсе непроизвольного запоминания и ухода от традиционного механического заучивания. В результате исследования выявлен ряд рациональных приемов запоминания иноязычной лексики, которые могут помочь изучающим иностранный язык более эффективно и быстро отложить в долговременную память подлежащие заучиванию лексические единицы. Ввиду того, что студенты профиля подготовки «Иностранный язык» в большинстве своем механически запоминают лексику, а потенциал рациональных приемов запоминания иноязычной лексики используется в учебном процессе по иностранному языку недостаточно, что подтверждается данными проведенного исследования, в статье приводятся некоторые методические рекомендации по более эффективной организации процесса усвоения иноязычной лексики.
\end{abstract}

\title{
Rational Techniques for Memorising Foreign Language Vocabulary in the System of University Students' Specialised Training: Theoretical and Practical Aspects
}

\author{
Kiryushina O. V.
}

Abstract. The study aims to identify ways to improve the quality of foreign language vocabulary acquisition by students of the "Foreign Language" training programme specialisation. The paper examines the peculiarities of teaching the lexical aspect of a foreign language, focuses, on the one hand, on the objective difficulties of learning new lexical units, on the other hand, on the importance of forming a sufficient active vocabulary in students. The researcher notes that students poorly memorise new foreign language vocabulary, sheds light on some reasons for this phenomenon, using statistical data of the study. One of the main reasons is the insufficient use of rational techniques for teaching foreign language vocabulary in the learning process. Further, the paper analyses a number of rational techniques for memorising foreign words, provides data on the extent to which these techniques are used by students, offers methodological recommendations for improving the quality of foreign language vocabulary acquisition. Scientific novelty of the study lies in an attempt to consider in a full and comprehensive manner the issue of memorising foreign language lexical units from the perspective of involuntary memorisation and avoiding traditional mechanical memorisation. As a result of the study, a number of rational techniques for memorising foreign language vocabulary that can help foreign language learners convert lexical units to memorise into long-term 
memory more effectively and quickly have been identified. Given that students of the "Foreign Language" training programme specialisation mostly memorise vocabulary mechanically and the potential of rational techniques for memorising foreign language vocabulary is not used enough in the educational process of foreign language teaching, which is confirmed by the data of the study, the paper provides some methodological recommendations for a more effective organisation of the process of foreign language vocabulary acquisition.

\section{Введение}

Актуальность темы исследования. Одним из важнейших аспектов обучения иностранному языку неизменно является лексический аспект. Будучи содержательной основой устного или письменного иноязычного высказывания, лексика представляет собой один из главных компонентов языковой компетенции, которая, в свою очередь, входит в состав иноязычной коммуникативной компетенции - главной стратегической цели обучения иностранному языку, закрепленной на уровне нормативно-правовых документов в любом типе учебного заведения, в том числе в высших учебных заведениях, ведущих подготовку обучающихся по профилю «Иностранный язык».

В то время как отсутствие академически правильного произношения или некоторое пренебрежение грамматическими нормами позволят осуществить пусть и не совсем полноценное и корректное в языковом отношении общение на иностранном языке, незнание лексики сделает иноязычную коммуникацию фактически абсолютно невозможной. Именно это обстоятельство и подчеркивает первостепенную роль лексики в осуществлении иноязычного речевого общения. Обладая крайне важной номинативной функцией, лексика фиксирует результаты познания человеком объектов окружающей действительности, дает каждому вновь познанному предмету или явлению свое имя. Не менее существенны и другие функции лексики: информационная, классифицирующая, знаковая, стилистическая, эстетическая, коммуникативная, контактная, эмотивная и др. (Морковкин, 2007, с. 44-50).

Лексический компонент иностранного языка объективно сложен: слово имеет звуковую и графическую формы, и они далеко не всегда совпадают; слово имеет определенное значение, которое может быть прямым и переносным, слово может быть также многозначным; слово имеет свои особенности сочетания и употребления, причем словосочетания могут быть свободными и устойчивыми. Необходимую лексическую единицу мало просто извлечь из памяти, необходимо еще ее правильно воспроизвести и употребить в речи, умело учитывая все вышеописанные нюансы. Кроме того, лексика - самый подвижный элемент языковой системы. Грамматика меняется относительно медленно, выученного и освоенного свода грамматических правил вполне хватит человеку, работающему в сфере иностранных языков, на всю жизнь. Лексику же выучить раз и навсегда не представляется возможным как ввиду ее огромного количества, так и вследствие ее постоянного изменения (архаизмы, неологизмы и др.).

Действительно, с точки зрения психологии одной из главных трудностей изучения лексики является ее «безразмерный» характер. В то же время для полноценного общения на иностранном языке необходим значительный по объему словарный запас (Фетисова, 2009, с. 24). Недостаточный и ограниченный вокабуляр обучающегося может стать сильным демотивирующим фактором в процессе обучения иностранному языку, что ведет к отказу от участия в иноязычной коммуникации (Кисель, Дубских, Бутова и др., 2019, с. 185).

Все упомянутые особенности делают обучение лексическому аспекту иностранного языка сложным, многогранным и требующим пристального внимания со стороны преподавателя процессом.

При обучении иностранному языку речь идет о формировании и развитии различных видов словарного запаса: активного, рецептивного и потенциального. Если рецептивный словарь формируется и в дальнейшем пополняется в основном за счет чтения и прослушивания аудиотекстов, а потенциальный словарь опирается на механизм языковой догадки, то активный лексический минимум требует особого внимания на занятиях по иностранному языку, так как он являет собой смысловую основу продуктивной иноязычной речи обучающихся.

Обучение иноязычной лексике включает в себя несколько взаимосвязанных этапов: введение и семантизацию лексических единиц (путем перевода, с помощью наглядности, через синонимы и антонимы, путем дефиниций на родном или иностранном языке, через контекст, путем словообразовательного анализа и т.д.); первичное закрепление; тренировку и применение; контроль; повторение. Каждый этап важен и вносит определенный вклад в формирование лексической компетенции обучающихся.

При изучении иностранного языка в качестве основного профиля в вузе словарный запас студентов должен быть весьма солидным и делиться на различные функциональные сферы: бытовую, учебную, культурную, общественную и т.д. Обучающиеся сталкиваются с огромным объемом иноязычной лексики, и перед ними остро встает проблема запоминания лексических единиц (Бетретдинова, Будник, 2014, с. 10). Учитывая большой объем лексических единиц и требования к уровню владения иноязычной лексикой в вузе, важно понимать, что процесс обучения лексике не может быть стихийным, он должен быть управляем как со стороны преподавателя, так и со стороны студента (Cudzich, 2012, с. 94).

Однако большинство практикующих преподавателей иностранного языка отмечают тот факт, что на заключительном этапе - этапе повторения (особенно отсроченного по времени) - зачастую обнаруживается, что большая часть пройденной активной лексики была благополучно забыта, несмотря на все усилия по ее тренировке и контролю. Постоянный доступ к различным гаджетам, удобство пользования электронными 
онлайн-словарями, которые всегда под рукой, снижение общеучебной мотивации, а также наблюдаемое в последние годы снижение потенциальной обучаемости и некоторые другие факторы активно способствуют тому, что студенты допускают все больше ошибок в употреблении иноязычной лексики вследствие ее плохого запоминания. Лексические единицы удерживаются ими на уровне кратковременной и оперативной памяти, но не переходят в долговременную память в том объеме, в котором это необходимо для успешного владения иностранным языком, что, в свою очередь, снижает качество преподавания иностранного языка в целом.

Кроме того, в рамках изучения данного вопроса нами было проведено исследование на факультете филологии и массовых коммуникаций Российского государственного профессионально-педагогического университета (филиал в г. Нижнем Тагиле). Исследование проводилось в период с декабря 2021 года по январь 2022 года. В нем приняли участие студенты 1-5 курсов очного отделения (95 человек), изучающих иностранный язык в качестве основного профиля. Лишь $22,2 \%$ опрошенных отметили, что легко и прочно запоминают новые лексические единицы. 59,3\% легко запоминают новые слова, но быстро их забывают. 18,5\% с трудом запоминают новую лексику. При этом никто из опрошенных не отметил в качестве причины плохую память. 51,9\% респондентов честно признались в том, что главной причиной плохого знания лексики является тот факт, что этому аспекту языка уделяется мало внимания с их стороны. 48,1\% опрошенных связывают непрочное запоминание лексики с недостаточным использованием в учебном процессе эффективных приемов запоминания иноязычной лексики.

Таким образом, актуальным является вопрос исследования и внедрения в учебный процесс по иностранному языку рациональных приемов, позволяющих быстрее и эффективнее запоминать иноязычные лексические единицы.

Для достижения цели исследования необходимо решить следующие задачи:

- изучить и описать наиболее эффективные рациональные приемы запоминания иноязычной лексики;

- выработать методические рекомендации для улучшения качества усвоения иноязычной лексики обучающимися.

Для написания данной статьи применялись следующие методы исследования: общетеоретические (анализ, синтез, обобщение, конкретизация, функциональный метод) и практические (описание, опрос, статистический метод).

Теоретической базой для написания статьи послужили труды отечественных и зарубежных исследователей: посвященные проблеме обучения лексическому аспекту иностранного языка (Бетретдинова, Будник, 2014; Кисель, Дубских, Бутова и др., 2019; Морковкин, 2007; Мохова, Назарова, Соколовская и др., 2019; Шамов, 2015; 2016; 2018a; 2018b); исследованию психологических механизмов непроизвольного запоминания лексики (Фетисова, 2009; 2011); эффективным приемам запоминания учебного материала (Еремеева, Баранова, 2016; Кувшинова, Фукс, 2014; Лысенко, 2011); использованию мнемотехник в учебном процессе по иностранному языку (Буняева, 2007; Гайдукова, 2016); стратегиям изучения лексики (Cudzich, 2012; Yang, 2017); диагностике и применению в обучении иностранному языку приоритетных учебных техник (Piepho, 1998; Rampillon, 1989; Rühl, 2021).

Практическая значимость исследования заключается в возможности использовать предложенные рациональные приемы запоминания иноязычной лексики в реальном учебном процессе по иностранному языку. Ввиду их универсальности приемы могут быть наполнены конкретным содержанием под любой иностранный язык и адаптированы для разного уровня владения иностранным языком.

\section{Рациональные приемы запоминания иноязычной лексики}

Под рациональными приемами запоминания иноязычной лексики мы понимаем специальные учебные техники, позволяющие более прочно запомнить необходимые иностранные слова и перевести максимальное количество лексических единиц в долговременную память обучающихся. При этом мы ни в коей мере не умаляем традиционный способ запоминания лексики, опирающийся на произвольное запоминание: многократное проговаривание и/или прописывание новых лексических единиц. Этот классический, самый простой и незамысловатой прием запоминания лексики, основанный на задействовании различных анализаторов (зрительного, слухового, речевого, двигательного), действительно проверен временем и позволяет прочно усвоить изучаемую лексику. Но, во-первых, этот способ не является единственно возможным. Во-вторых, обучающиеся принадлежат к различным когнитивным типам («левополушарники» и «правополушарники»; аналитики и синтетики; аудиалы, визуалы и кинестетики и т.д.), поэтому нет и не может быть одного, подходящего для всех, абсолютно универсального способа запоминания иноязычной лексики. Чем больше техник предлагается обучающимся, тем больше вероятность того, что каждый из них найдет подходящий для себя вариант. Важным фактором успеха в этом вопросе, на наш взгляд, является возможность опоры на непроизвольое запоминание. Господствующая в отечественной методике преподавания иностранных языков направленность на произвольную память, неуклонное соблюдение принципа сознательности и требование приложения постоянных волевых усилий не всегда способствуют успеху на поприще иностранных языков у современных обучающихся. Нам представляется, что подключение механизмов непроизвольного запоминания позволит сократить время и силы студентов на изучение иноязычной лексики и добиться более высокого качества усвоения учебного материала (Фетисова, 2011, с. 162).

Следует отметить, что в основе всех рациональных приемов изучения иноязычной лексики лежат те или иные учебные стратегии: когнитивные (kognitive Strategien), стратегии повторения (Wiederholungsstrategien), 
организационно-структурирующие стратегии (strukturierende Organisationstrategien), генеративные стратегии (generative Strategien). Все они, в свою очередь, управляются метакогнитивными стратегиями (планирования, регуляции, контроля) (Yang, 2017, с. 106).

Рассмотрим некоторые из рациональных приемов запоминания иноязычной лексики.

1. Прием ассоциативного запоминания

Суть данного приема состоит в подборе к подлежащему заучиванию иностранному слову созвучного слова на родном языке. Затем к возникшему созвучному слову необходимо найти некую смысловую ассоциацию. Это помогает отложить слово в памяти без механического заучивания (Кувшинова, Фукс, 2014, с. 129).

Например: немецкое слово der Fuchs - лиса. Созвучно с русским словом «фокусы». Придумываем ассоциацию: «Хитрая лиса всегда выкидывает разные фокусы».

2. Запоминание слова в логической взаимосвязи с другими словами

Лексика легче запоминается не в изолированном виде, а в определенной логической связи с другими словами. При этом тип связи может быть различным.

M. Yang (2017, с. 103) выделяет пять типов такой связи (Табл. 1).

Таблица 1. Типы логической связи слов

\begin{tabular}{|l|l|l|}
\hline 1 & Koordinationen (координация) & Salz + Pfeffer + Senf (соль + перец + горчица) \\
\hline 2 & Kollokationen (коллокация) & Salz streuen; Auto fahren (посыпать солью; водить автомобиль) \\
\hline 3 & Subordinationen (субординация) & Vogel: Spatz, Ente, Adler, Eule (птица: воробей, утка, орел, сова) \\
\hline 4 & Synonyme (синонимы) & berichtigen = korrigieren (исправлять = корректировать) \\
\hline 5 & Antonyme (антонимы) & gut - böse; groß - klein (добрый - злой; большой - маленький) \\
\hline
\end{tabular}

Группировка слов по разным признакам, установление различных связей между ними, перекодирование материала являются мощным фактором увеличения объема информации для переработки человеческим мозгом (Лысенко, 2011, с. 413).

3. Составление примеров и написание историй со словами

Лексика легче запоминается не в изолированном виде, а в контексте, где можно продемонстрировать сочетательные возможности слова. Эффективный способ запоминания новых лексических единиц - это их применение в речи. Составление характерных примеров и ярких сюжетных историй поможет надолго отложить нужные лексические единицы в памяти.

4. Использование техники Мind Мар (ментальная карта)

Ментальная карта - это схема, которая объединяет информацию в виде круговой структуры вокруг основной темы или идеи. Вместо текста, состоящего из предложений, диаграммы связей отображают информацию в виде ключевых слов, коротких словосочетаний и изображений. Главный принцип построения интеллектуальной карты - наглядность. Как правило, в центре данной схемы размещают ключевое понятие или рисунок, по разные стороны от него рисуют «ветви», ведущие к составным элементам, пунктам, категориям основного понятия. С помощью графически изображенных стрелок можно установить связи между элементами схемы (Кирилюк, 2019) (Рис. 1).

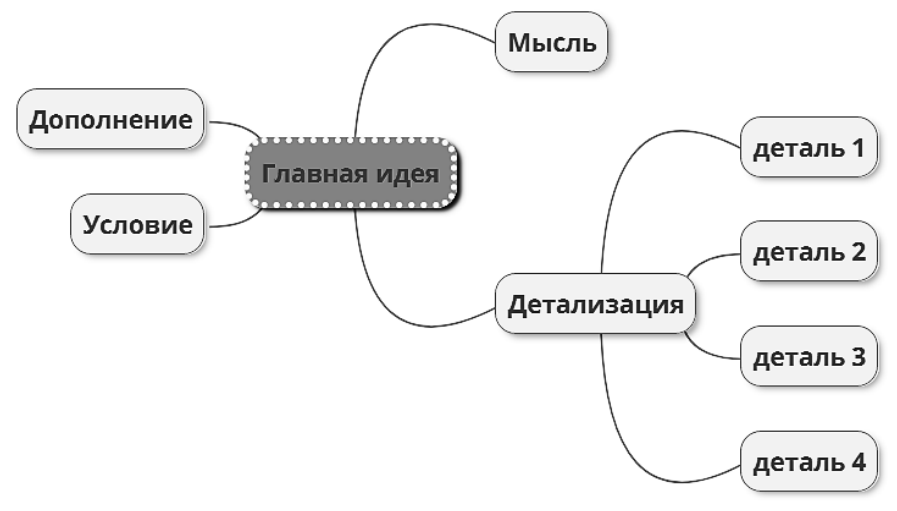

Рисунок 1. Пример ментальной карты

\section{5. Техника визуализации}

Любой процесс может быть упрощен с помощью визуализации. Запоминание лексики не является исключением. Необходимо представить себе предмет или явление, называемое словом, подумать о его качествах (цвет, запах, вкус и др.). В случае с абстрактными словами можно подумать об эмоциях или представить ситуацию, где это слово может употребляться. Кроме того, техника визуализации может применяться и более буквально: тематические картинки с подписями на иностранном языке, где картинки заменяют перевод слов.

6. Применение различных мнемотехник

Для развития памяти - важнейшего механизма изучения иностранного языка - существует множество мнемотехнических приемов, некоторые из них мы хотели бы продемонстрировать в качестве примера. 
Прием «алфавит знаний» помогает запомнить новые слова в порядке букв немецкого алфавита в увлекательной форме. Для начала следует выбрать наиболее подходящую лексическую тему и отобрать лексические единицы, начинающиеся на разные буквы. Затем полученные слова нужно расставить в алфавитном порядке (Буняева, 2007).

Например:

Ein Arzt fand einen Apfel in der Allee (Врач нашел яблоко на аллее).

Ein Bauer isst Banane im Bett (Крестьянин ест банан в постели).

Ein Chef sitzt mit einem Computer im Café (Шеф сидит за компьютером в кафе).

Eine Dame kaufte Dessert in der Disko (Дама купила десерт на дискотеке).

Приведем еще один пример мнемотехники, используемой для самодиагностики.

Внимательно смотрите на ряд слов в течение минуты, а затем закройте их рукой. Постарайтесь вспомнить как можно больше слов и записать их на листок. Затем проверьте себя.

Wasser - Herz - Hase - Leben - Kopf - Linie - Kindheit - Tür - Körper - Aussehen - Augen - Haus - Schlaf - Gefühl Wolke - Charakter - Bild - Verstand - Schulzeit - Schnee - Beruf - Stift - Kuh - Hügel - Feld - Doppelkinn - Hand.

(Вода - сердце - заяц - жизнь - голова - линия - детство - дверь - туловище - внешний вид - глаза - дом сон - чувство - облако - характер - картина - разум - школьные годы - снег - профессия - карандаш - корова холм - поле - двойной подбородок - рука.)

Проанализируйте результаты. Запомнили ли Вы слова Wasser, Hand (вода, рука)? Это очень характерно. Мы, как правило, легче всего запоминаем информацию, размещенную в самом начале и самом конце. Запомнили ли Вы слово Doppelkinn (двойной подбородок)? Это тоже обычное явление. Мы часто хорошо запоминаем необычные слова, которые выглядят иначе, чем другие. Записали ли Вы слова, связанные с человеком, в одну группу? Так делает большинство людей, потому что сгруппированные слова легче запоминаются. Возможно, Вы записали слова, которых не было в списке. Так тоже иногда случается.

7. Картотека слов (die Vokabelkartei)

Полезным приемом заучивания иноязычной лексики является картотека (Rampillon, 1989, с. 98) (Рис. 2).

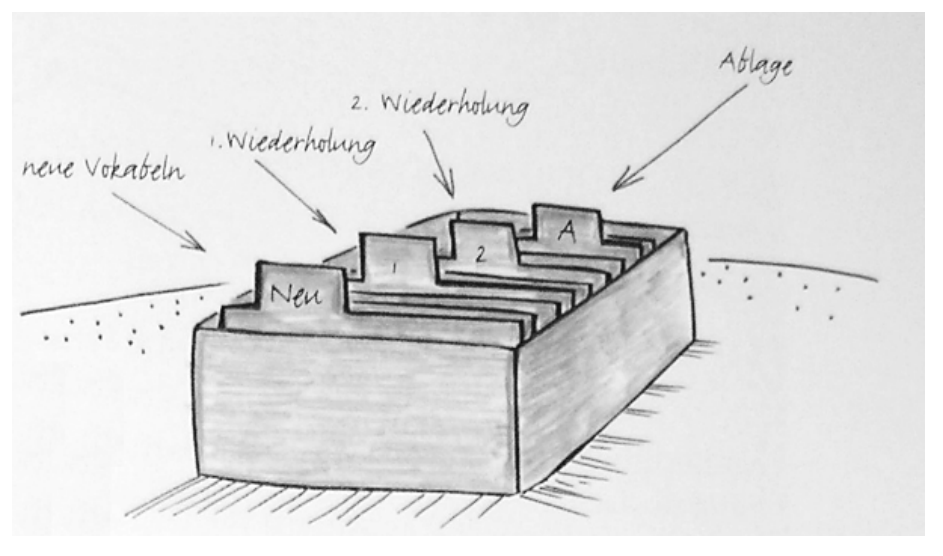

Рисунок 2. Картотека слов

Пояснения к рисунку: neue Vokabeln - новые слова; 1. Wiederholung - первое повторение;

2. Wiederholung - второе повторение; Ablage - склад.

С помощью картотеки можно тренировать новые слова, повторять их, заучивать в определенной взаимосвязи, распределять по группам и т.д. Для создания картотеки понадобятся: коробка, карточки или листочки, алфавитный регистратор. На словарной карточке пишется слово, его перевод (с обратной стороны карточки), множественное число, примеры употребления, словосочетания. Карточки с новыми лексическими единицами помещают впереди, в рубрику «Слова для заучивания». Начинать работу нужно именно с этой рубрики. Если слово сразу же всплывает в памяти, то карточку можно переместить в самый конец картотеки. Если слово не запоминается, то его перемещают в рубрику «Для первого повторения». Если и потом слово все же не откладывается в памяти, то оно перемещается в рубрику «Для второго повторения». Слова, которые находятся в конце картотеки, полезно время от времени тоже повторять. Лексические единицы, которые даже после повторения очень плохо запоминаются, можно снова переложить в рубрику «Новые слова».

8. Размещение лексических единиц в зоне вероятного внимания

Данный прием особенно эффективен при изучении лексики бытового характера, когда мы можем расклеить повсюду в квартире или аудитории яркие стикеры с иностранными словами. Они постоянно находятся в зоне нашего внимания и быстро запоминаются.

9. Прием внешнего контроля

Эффективный способ проверить степень усвоения лексических единиц после их заучивания - проверка другим человеком (по тетради, по списку и т.д.). Этим человеком может быть однокурсник, кто-то из домашних. Эффект будет еще выше, если обе стороны заинтересованы в результате и могут побеседовать с применением новых лексических единиц в речи или осуществить взаимоконтроль. 
10. Диалог с собой / внутренний монолог на иностранном языке

Если не получилось найти партнера для беседы на иностранном языке и взаимоконтроля, то можно вполне обойтись своими силами. Данный прием в немецкой дидактике называется das Selbstgespräch. И он безусловно заслуживает внимания. Проговаривание, описание, проигрывание каких-то ситуаций средствами иностранного языка - гораздо более эффективный способ запоминания лексики, потому что он имеет ярко выраженный практический характер. Лексика не просто теоретически заучивается, а сразу находит применение в речи. А регулярные речевые тренировки будут способствовать достижению существенного прогресса в изучении иностранного языка (Gelman, 2018).

11. Метод интервальных повторений

На основе открытой и описанной немецким психологом Германом Эббингаузом кривой забывания (1885 г.) были разработаны различные методики запоминания, базирующиеся на регулярных повторениях через определенные временные интервалы. Интервалы для повторения могут быть различными (как в плане их количества, так и в плане их продолжительности), но главным является тот факт, что без регулярных тренировок невозможно качественно запомнить информацию. Наиболее благоприятный момент для запоминания - на условной «грани забывания». Своевременное повторение меняет кривую забывания и позволяет новым лексическим единицам отложиться в долговременной памяти (Еремеева, Баранова, 2016, с. 296).

Метод интервальных повторений можно сочетать с описанным в пункте 6 методом картотеки слов. Рубрики в картотеке можно изначально заложить в зависимости от временных интервалов: новые слова, спустя 1-3 дня, спустя неделю, спустя 2-4 недели, спустя 3 месяца (Rühl, 2021, с. 3) (Рис. 3).

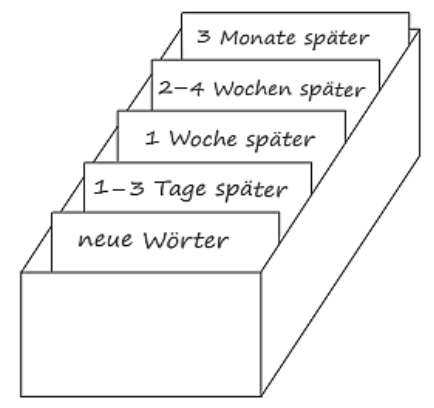

Рисунок 3. Вариант картотеки слов с временными интервалами

\section{2. Игровые приемы}

Различные игровые приемы помогают запоминать лексические единицы в доступной форме и с элементом развлечения: разгадывание и составление кроссвордов, языковые шарады, игры в отгадывание слов по различным признакам, составление из одного длинного слова множества других, игра в виселицу, игра «в слова» (назвать как можно больше слов на одну букву, назвать по очереди слова на последнюю букву предыдущего слова, игра в географию и др. вариации), поиск лишних слов в цепочке, «мозговой штурм» (очень быстро назвать как можно больше слов по определенной теме) и т.д.

Лексические игры чрезвычайно эффективны и уместны в любом возрасте, на любом этапе обучения, при любом составе игроков и даже в одиночестве.

13. Рифмовки и стихи

Техника составления рифмовок полезна для запоминания новых лексических единиц в стихотворении. Например, при изучении времен года можно предложить такую рифмовку:

Die Jahreszeit - времена года,

Чудесная погода.

Der Frühling - весна.

Все проснулось ото сна.

Der Sommer - лето.

В цветы и зелень все одето.

Der Herbst - осень.

С полей все уносим.

Der Winter - зима.

Опустели закрома (Кирдакова, 2005).

Или другой пример, основанный на сходстве немецкого и английского слова: free (englisch) - frei (deutsch): Eins, zwei, drei, ich bin frei, frei heißt free, das vergess ich nie (free по-английски - frei по-немецки: Один, два, три, я свободен, frei - это free, я это никогда уже не забуду).

14. Прием составления акронимов

Из первых букв слов, которые нужно запомнить, можно сложить новое слово. Важно, чтобы слова были из одной тематической группы (например, еда).

Интересный пример акронима в узкой профессиональной сфере на материале английского языка приводит M. А. Гайдукова (2016, с. 255). Аббревиатура ASSIST позволяет запомнить последовательность действий пилота 
при возникновении внештатной ситуации: Acknowledge (получить подтверждение), Separate (обеспечить эшелонирование), Silence (ввести режим радиомолчания), Inform (проинформировать экстренные службы), Support (обеспечить необходимую поддержку), Тіmе (дать пилотам время на обдумывание последующих действий).

Перечень приведенных рациональных приемов изучения иноязычной лексики не является исчерпывающим, однако он наглядно демонстрирует разнообразие учебных техник запоминания новых лексических единиц в процессе обучения иностранному языку. Какие же из вышеописанных приемов запоминания лексики используют обучающиеся в учебном процессе?

Подавляющее большинство студентов (83,3\%) отметили, что самым предпочтительным способом запоминания иноязычной лексики для них является многократное проговаривание и/или прописывание новых лексических единиц, то есть по сути - механическое запоминание. Эти данные подтверждают упомянутый выше факт недостаточного использования в учебном процессе рациональных приемов запоминания иноязычной лексики. 38\% респондентов используют ассоциативный метод. 36\% - составляют примеры со словами. 30\% - ведут специальную словарную тетрадь. 26\% опрошенных прибегают к технике внешнего контроля. $22 \%$ - группируют слова по темам. $12 \%$ - пользуются лексическими каточками. $2 \%$ респондентов используют рифмовки и стикеры. Все остальные приемы запоминания лексики студентами не используются.

Таким образом, полученные результаты исследования убедительно свидетельствуют о том, что богатый потенциал рациональных приемов запоминания иноязычной лексики используется в учебном процессе по иностранному языку недостаточно. Поэтому важной задачей преподавателя иностранного языка в данной ситуации представляется создание условий для эффективного запоминания обучающимися иноязычной лексики в виде доведения до них рациональных приемов запоминания лексических единиц, демонстрации их потенциальных возможностей. Это поможет обучающимся выбрать подходящую для себя стратегию изучения лексики иностранного языка и более эффективно выстроить индивидуальную образовательную траекторию.

\section{Методические рекомендации для улучшения качества усвоения лексики обучающимися}

Данные проведенного исследования позволили диагностировать недостаточное использование студентами рациональных приемов запоминания иноязычной лексики, что наводит на мысли о необходимости для преподавателя выстраивать более тщательный алгоритм работы с активным лексическим минимумом.

Общепринятые этапы работы над лексикой (презентация, семантизация, первичное закрепление, тренировка, повторение), которые, как правило, осуществляются в рамках учебной аудитории при непосредственном контроле со стороны преподавателя, должны сопровождаться более тщательной самостоятельной работой за пределами аудитории, где важным инструментом опосредованного контроля будет обеспечение обучающихся рациональными приемами запоминания иноязычной лексики.

Первым и очень важным этапом работы над запоминанием иноязычной лексики должна стать так называемая самодиагностика. Обучающимся необходимо понять для самих себя, какой способ запоминания новой лексики будет наиболее предпочтительным. Приведем пример самодиагностики из немецкой дидактики (Piepho, 1998, с. 27) (Табл. 2).

Таблица 2. Selbstdiagnostik “Wie lerne ich am besten?”

\begin{tabular}{|l|c|c|}
\hline \multicolumn{1}{|c|}{ Ich lerne Wörter am besten, } & gut & schlecht \\
\hline wenn ich sie mehrmals aufschreibe und aufhänge. & & \\
\hline wenn ich die Wörter im Gespräch höre. & & \\
\hline wenn ich die Wörter gebrauche. & & \\
\hline wenn ich sie für eine Prüfung lernen muss. & & \\
\hline wenn ich sie im Gespräch benutze. & & \\
\hline wenn ich sie laut vor mich hinspreche. & ja & nein \\
\hline wenn ..................................................................... & \\
\hline & & \\
\hline Ich schreibe neue Vokabeln ins Heft ohne bestimmtes System. & & \\
\hline Ich notiere sie täglich in einem Extravokabelheft. & & \\
\hline Ich ordne sie nach Sachgebieten. & & \\
\hline Ich schreibe jedes wichtige Wort auf eine separate Karteikarte. & & \\
\hline Ich lese alle neuen Vokabeln ein paar Mal durch. & & \\
\hline Regelmäßig lerne ich kleinere Einheiten von bis zu zehn Wörtern auf einmal. & \\
\hline Ich lerne neue Wörter in einem Sinnzusammenhang. & & \\
\hline Ich wiederhole meine Vokabelkartei bei jeder Gelegenheit, z.B. in der U-Bahn. & \\
\hline
\end{tabular}

Комментарий на русском языке к таблище: предлагается проанализировать и отметить в таблице, плохо или хорошо запоминаются иностранные слова при различных условиях (если я их записываю, развешиваю, если слышу в разговоре, если должен выучить их к экзамену, если я их громко проговариваю, свои варианты ответов); требуется подтвердить или опровергнуть несколько утверждений (я записываю слова в словарную тетрадь без определенной системы, я ежедневно записываю новые слова с специальную тетрадь, я распределяю слова по тематике и сферам, я записываю слова на карточках, я несколько раз просматриваю новые слова, я регулярно учу новые порции слов (до 10), я заучиваю слова в логической взаимосвязи, я повторяю слова из картотеки при любой возможности, например в метро и т.д.). 
Если обучающийся не может сразу определиться с наиболее подходящими для него индивидуальными приемами изучения иноязычной лексики, то возможно апробировать несколько из них и выявить их эффективность на практике. Некоторые эффективные приемы работы с лексикой преподаватель может продемонстрировать на занятии по иностранному языку: мнемотехники, ассоциативное запоминание, тематическая группировка слов, акронимы и др. В процессе аудиторной работы достаточно просто реализовать приемы визуализации и технику составления ментальных карт. Представляется, что данные приемы будут не только способствовать усвоению иноязычной лексики, но и стимулировать интерес студентов к изучению иностранного языка. Можно привлечь студентов в рамках изучения конкретной разговорной темы к изготовлению картотеки слов, чтобы наглядно продемонстрировать определенной академической группе реализацию этого приема запоминания лексических единиц.

Совершенно не сложно интегрировать игровые приемы изучения иноязычной лексики в учебный процесс по иностранному языку. Например, можно предложить игру в «снежный ком» в конце занятия с целью лучшего запоминания новых лексических единиц или составление студентами кроссвордов по изучаемым разговорным темам и обмен ими на занятии или в качестве дополнительного домашнего задания.

Представляется особенно важным довести до сведения студентов основы интервального повторения лексики. Обучающиеся могут экспериментальным путем определить наиболее удобные для себя интервалы повторения лексики с целью достижения максимального эффекта для ее запоминания.

Важно учитывать, что в процессе обучения лексическому аспекту иностранного языка обучающиеся сами должны определять наиболее значимые для себя лексические единицы по определенной разговорной теме, способы их запоминания, приемы их повторения. Только в этом случае студенты выстраивают персональный образовательный маршрут в независимости от их уровня владения иностранным языком (Мохова, Назарова, Соколовская и др., 2019).

Дальнейшими шагами со стороны преподавателя будет создание условий для закрепления и тренировки выученных лексических единиц путем выполнения различного рода лексических упражнений. При этом крайне важную роль будет играть постоянное повторение уже изученных лексических единиц, осуществление в учебном процессе так называемой «рециркуляции лексики». Только постоянное возвращение к изученной лексике в новых коммуникативных ситуациях будет способствовать ее прочному усвоению.

Предложенные методические рекомендации, направленные на выстраивание четкого алгоритма по обучению лексике иностранного языка, а именно - сочетание аудиторной работы при непосредственном контроле со стороны преподавателя и самостоятельной работы при опосредованном контроле - будут, на наш взгляд, способствовать более качественному усвоению иноязычной лексики студентами профиля «Иностранный язык».

\section{Заключение}

Большой объем активной лексики, подлежащий изучению студентами профиля «Иностранный язык», представляет для обучающихся значительную трудность в усвоении. Поэтому проведенное исследование позволило прийти к следующим выводам:

- Рассмотренные в рамках данного исследования рациональные приемы работы с иноязычной лексикой, опирающиеся в большей степени на непроизвольные механизмы запоминания, призваны способствовать переводу максимального количества изучаемых лексических единиц в долговременную память обучающихся.

- Проведенное среди студентов вуза исследование предпочтительных приемов запоминания иноязычной лексики продемонстрировало недостаточное использование обучающимися потенциала эффективных приемов изучения лексики иностранного языка. В связи с этим фактом внедрение в процесс обучения лексическому аспекту иностранного языка рациональных приемов запоминания иноязычной лексики, а также выстраивание более четкого алгоритма работы с ней представляются важными инструментами управления самостоятельной работой студентов по усвоению активного лексического минимума, что, в свою очередь, будет способствовать повышению качества обучения на факультетах, осуществляющих профильную подготовку студентов.

Перспективы дальнейшего исследования видятся в разработке более детальных методических рекомендаций для преподавателей и студентов с целью повышения качества обучения лексическому аспекту иностранного языка с акцентом на рациональные приемы запоминания иноязычной лексики. Подробные методические рекомендации будут, на наш взгляд, способствовать большей управляемости процесса обучения лексической стороне иноязычной речи.

\section{Источники | References}

1. Бетретдинова И. А., Будник Е. А. Особенности обучения лексическому компоненту речи на различных этапах (на материале английского языка) // Экономика, статистика, информатика. 2014. № 2.

2. Буняева Н. Ю. Использование мнемотехник в преподавании немецкого языка // Библиотечка «Первого сентября». Серия «Немецкий язык». 2007. № 5 (17).

3. Гайдукова М. А. Мнемотехника как интенсивный метод преподавания авиационного иностранного языка в вузе // Вопросы методики преподавания в вузе. 2016. № 5.

4. Еремеева Г. Р., Баранова А. Р. Метод интервальных повторений при изучении иностранного языка // Бюллетень науки и практики. 2016. № 7. 
5. Кирдакова Н. В. Методические материалы в стихотворной форме для использования на уроках немецкого языка. 2005. URL: https://urok.1sept.ru/articles/213299

6. Кирилюк О. Карта mind map: легкое планирование и структурирование. 2019. URL: https://blog. checkiant.com/ru/blog-o-produktivnosti/166-tekhnologiya-mind-mapping

7. Кисель О. В., Дубских А. И., Бутова А. В., Зеркина Н. Н. Проблемы, связанные с обучением лексике студентов неязыковых специальностей МГТУ им. Г. И. Носова // Современные наукоемкие технологии. 2019. № 7.

8. Кувшинова Н. Н., Фукс Е. А. Эффективные приемы запоминания иноязычного лексического материала, ориентированные на индивидуальные особенности обучающихся // Magister Dixit. 2014. № 2 .

9. Лысенко Н. Е. Развитие приемов запоминания учебного материала при изучении русского и иностранного языков // Ученые записки Орловского государственного университета. Серия «Гуманитарные и социальные науки». 2011. № 6.

10. Морковкин В. В. Основные функции лексических единиц // Вестник Российского университета дружбы народов. Серия «Вопросы образования: языки и специальность». 2007. № 1.

11. Мохова О. Л., Назарова Н. Б., Соколовская М. А., Башеров О. И. Обучение иноязычной лексике в неязыковом вузе // Современные проблемы науки и образования. 2019. № 2. URL: https://science-education.ru/ $\mathrm{ru} /$ article/view?id $=28780$

12. Фетисова А. А. Методические возможности использования непроизвольного запоминания при обучении лексике // Вестник Московского университета. Серия 19 «Лингвистика и межкультурная коммуникация». 2009. № 1.

13. Фетисова А. А. Психологические механизмы усвоения иноязычной лексики // Вестник Московского университета. Серия 19 «Лингвистика и межкультурная коммуникация». 2011. № 2.

14. Шамов А. Н. Иноязычные лексические механизмы и стратегии как основа формирования лексической компетенции // Теория и методика обучения иностранным языкам: традиции и инновации. Шатиловские чтения: сб. науч. тр. / Российский государственный педагогический университет им. А. И. Герцена; СанктПетербургский политехнический университет Петра Великого. СПб.: ПОЛИТЕХ-ПРЕСС, 2018а.

15. Шамов А. Н. Лексическая сторона иноязычной речи и технологии обучения ей // Иностранные языки в школе. 2018b. № 9.

16. Шамов А. Н. Приемы эффективного запоминания лексики на уроках немецкого языка // Иностранные языки в школе. 2015. № 2.

17. Шамов А. Н. Технологии обучения лексической стороне иноязычной речи: монография. Н. Новгород, 2016.

18. Cudzich B. Vokabellernen (ohne) Vergessen (mit) Vokabellernstrategien // Glottodidactica. 2012. № 39 (1).

19. Gelman G. 5 Strategien, um schnell und einfach Vokabeln zu lernen. 2018. URL: https://www.sprachheld.de/ vokabeln-lernen-tipps/

20. Piepho H. E. Wie lerne ich am besten? // Fremdsprache Deutsch. 1998. № 2 .

21. Rampillon U. Lerntechniken im Fremdsprachenunterricht. Handbuch. München: Max Hueber Verlag, 1989.

22. Rühl E. Wortschatzarbeit. Wie bleiben neue Wörter leichter im Kopf? // Fremdsprache Deutsch. 2021. № 64.

23. Yang M. Effektivität von Vokabellernstrategien im DaF-Unterricht in China: Inaugural-Dissertation zur Erlangung der Doktorwürde des Fachbereichs Germanistik und Kunstwissenschaften der Philipps-Universität Marburg. Marburg, 2017.

\section{Информация об авторах | Author information}

RU Кирюшина Ольга Викторовна ${ }^{1}$, к. пед. н.

${ }^{1}$ Российский государственный профессионально-педагогический университет, филиал в г. Нижнем Тагиле

EN Kiryushina Olga Victorovna ${ }^{1}, \mathrm{PhD}$

${ }^{1}$ Russian State Vocational and Pedagogical University, the branch in Nizhniy Tagil

${ }^{1}$ olga_kiryushina_@mail.ru

\section{Информация о статье | About this article}

Дата поступления рукописи (received): 11.01.2022; опубликовано (published): 28.02.2022.

Ключевые слова (keywords): лексический аспект иностранного языка; иноязычная лексика; произвольное и непроизвольное запоминание; рациональные приемы запоминания; lexical aspect of a foreign language; foreign language vocabulary; voluntary and involuntary memorisation; rational memorisation techniques. 